\title{
Pengukuran Dosis Eksternal yang diterima oleh Mahasiswa Praktikum Teknik Radiografi di Laboratorium Radiologi Universitas Baiturrahmah Padang
}

\author{
Dila Nelvo Dasril, Oktavia Puspita Sari \\ Program Studi DIII radiologi, Universitas Baiturrahmah, Padang, Indonesia, 35141 \\ Email : ${ }^{\left({ }^{*}\right)}$ dilanelvodasril@atro.unbrah.ac.id, ${ }^{(b)}$ oktaviapuspitasari@atro.unbrah.ac.id
}

Diterima (07 Oktober 2019), Direvisi (15 Desember 2019)

\begin{abstract}
The utilization of ionizing radiation in the form of X-rays in addition to providing benefits to the medical world also has the potential to have a detrimental effect on workers, patients and, society. Radiation protection is a very important aspect of controlling this adverse effect. Every utilization of ionizing radiation must have endeavored so that the reception of radiation doses by radiation workers is always as low as possible so that the prescribed dose of limitation value is not exceeded. The dose of limitation for apprentices and students who are as low as 18 years old, who are carrying out training or practical work, or who because of their educational needs are forced to use a source of ionizing radiation, the same as the dose of limitation that applies to radiation workers. Dose limit values for radiation workers must not exceed $20 \mathrm{mSv}$ (twenty millisieverts) per year on average for five consecutive years. Determination of the external radiation dose received by practicum students at the Baiturrahmah University Radiology Laboratory use Thermoluminisensi Detector aims to calculate how much the external radiation dose received by students during carrying out one course. Based on the results of the study found that the measurement of external radiation dose received by the student is $0 \mathrm{mSv}$ or there is no scattering radiation received by students, this is because at the time of exposure they are in the correct position that is behind the control panel wall that has been coated with Lead (Pb).
\end{abstract}

Keywords: Dose of Limitation, ,Radiation dose, Radiation worker, Thermoluminisensi Detector

\begin{abstract}
Abstrak. Pemanfaatan radiasi pengion berupa sinar-X selain memberikan manfaat bagi dunia kedokteran, juga berpotensi memberikan efek merugikan bagi pekerja, pasien dan masyarakat. Proteksi radiasi merupakan aspek yang sangat penting dalam pengendalian efek yang merugikan ini. Setiap pemanfaatan radiasi pengion harus diusahakan agar penerimaan dosis radiasi oleh pekerja radiasi selalu serendah mungkin sehingga nilai batas dosis (NBD) yang telah ditetapkan tidak terlampaui. Nilai batas dosis untuk para magang dan siswa yang berumur serendahrendahnya 18 tahun, yang sedang melaksanakan latihan atau kerja praktek, atau yang karena keperluan pendidikannya terpaksa menggunakan sumber radiasi pengion, sama dengan nilai batas dosis (NBD) yang berlaku untuk pekerja radiasi. Nilai batas dosis untuk pekerja radiasi tidak boleh melampaui $20 \mathrm{mSv}$ (duapuluh milisievert) pertahun rata-rata selama lima tahun berturut-turut. Penentuan dosis radiasi ekternal yang diterima oleh mahasiswa praktikum di Laboratorium Radiologi Universitas Baiturrahmah menggunakan Thermoluminisensi Detector (TLD) bertujuan untuk menghitung seberapa besar dosis radiasi eksternal yang diterima oleh mahasiswa selama melaksanakan satu mata kuliah. Berdasarkan hasil penelitian didapatkan bahwa pengukuran dosis radiasi eksternal yang diterima mahasiswa tersebut adalah $0 \mathrm{mSv}$ atau tidak terdapat radiasi hambur yang diterimaoleh mahasiswa, hal ini dikarenakan pada saat dilakukan ekspose mereka berada pada posisi yang benar yaitu dibelakang dinding kontrol panel yang sudah dilapisi dengan Timbal $(\mathrm{Pb})$.
\end{abstract}

Kata kunci: Dosis radiasi, Nilai Batas Dosis, Pekerja Radiasi, Thermoluminisensi Detector 
Dela Nelvo Dasril: Pengukuran Dosis Eksternal Yang Diterima Oleh Mahasiswa Praktikum Teknik Radiografi di Laboratorium Radiologi Universitas Baiturrahmah Padang)

\section{PENDAHULUAN}

Pemanfaatan radiasi pengion berupa sinar-X selain memberikan manfaat bagi dunia kedokteran, juga berpotensi memberikan efek merugikan bagi pekerja, pasien dan masyarakat. Proteksi radiasi merupakan aspek yang sangat penting dalam pengendalian efek yang merugikan ini [1]. Setiap pemanfaatan radiasi pengion harus diusahakan agar penerimaan dosis radiasi oleh pekerja radiasi selalu serendah mungkin sehingga nilai batas dosis (NBD) yang telah ditetapkan tidak terlampaui [2]. NBD untuk para magang dan siswa yang berumur serendahrendahnya 18 tahun, yang sedang melaksanakan latihan atau kerja praktek, atau yang karena keperluan pendidikannya terpaksa menggunakan sumber radiasi pengion, sama dengan NBD yang berlaku untuk pekerja radiasi [3]. Nilai batas dosis untuk pekerja radiasi tidak boleh melampaui $20 \mathrm{mSv}$ (duapuluh milisievert) pertahun rata-rata selama lima tahun berturut-turut [4].

Pemanfaatan radiasi di bidang kedokteran memberikan kontribusi yang cukup besar terhadap paparan radiasi yang diterima manusia. Sekitar $15 \%$ sumber radiasi yang diterima manusia diperoleh dari aktivitas pemanfaatan radiasi di bidang kesehatan yang meliputi radiodiagnostik, radioterapi dan kedokteran nuklir. Kontribusi terbesar dosis radiasi yang diterima oleh penduduk dunia adalah dari aplikasi radiasi di bidang medik, dan lebih dari $90 \%$ kontribusi ini berasaldari sinar X diagnostik. Keselamatan pekerja radiasi tidak terlepas dari dosis radiasi. Berdasarkan laporan pemantauan dosis pekerja radiasi, pada tahun 2013 nilai dosis tertinggi yang diterima pekerja radiasi di Indonesia sebesar $21,85 \mathrm{mSv}$, nilai dosis terendah $1,20 \mathrm{mSv}$, dan rata-rata $1,20 \mathrm{mSv}$. Pada tahun 20112012 nilai minimum dosis yang diterima pekerja radiasi masing-masing sebesar 1,20 $\mathrm{mSv}$ dan nilai maksimum dosis yang diterima masing-masing sebesar $25,03 \mathrm{mSv}$ dan 23,64 mSv. Sedangkan nilai rata-rata dosis yang diterima secara keseluruhan sebesar 1,20 mSv, nilai ini di bawah NBD (Nilai Batas Dosis) yang dipersyaratkan yaitu sebesar $20 \mathrm{mSv}$ [5].

Maka perlu dilakukan usaha yang berhubungan dengan Keselamatan dan Kesehatan Kerja (K3) bagi pekerja radiasi, masyarakat dan lingkungannya. Selain keuntungan yang diperoleh, radiasi mengandung potensi bahaya bagi manusia dan lingkungan, apabila dalam pelaksanaannya tidak mengikuti prosedur K3 radiasi yang telah ditentukan. Ada 2 (dua) macam pemonitoran untuk dapat memberikan perlindungan kepada manusia dari paparan radiasi yaitu pemonitoran paparan radiasi terhadap tempat kerja dan pemonitoran paparan radiasi terhadap personil yang bekerja. Tujuan K3 radiasi untuk mencegah efek non stokastik (deterministik) dan membatasi peluang terjadinya efek stokastik sampai pada tingkat yang dapat diterima. Setiap penyinaran pada seluruh tubuh menyebabkan efek yang berbeda pada berbagai macam jaringan, maka untuk perlindungan terhadap efek stokastik perlu ditetapkan Nilai Batas Dosis atau NBD yang berdasarkan pada resiko total dari semua jaringan yang mendapat penyinaran [6].

Dalam pemanfaatan radiasi pengion, faktor keselamatan terhadap para pekerjanya harus mendapat prioritas utama. Hal tersebut didasarkan pada Peraturan Pemerintah (PP) RI No.63 Tahun 2000 tentang Keselamatan dan Kesehatan terhadap Radiasi Pengion $(\alpha, \beta, \gamma, \mathrm{x}, \mathrm{n})$, yang umum disebut keselamatan radiasi. Dalam pasal 10 disebutkan bahwa "Pengusaha instalasi harus mewajibkan setiap pekerja radiasi untuk memakai peralatan pemantau dosis perorangan, sesuai dengan jenis instalasi dan sumber radiasi yang digunakan (ayat 1)". Untuk itu, para pekerja radiasi perlu memakai peralatan pemantau dosis perorangan untuk 
mendapatkan layanan pemantauan dosis tara perorangan secara rutin terutama dari sumber radiasi eksternal, sehingga dosis yang diterima oleh para pekerja radiasi selama menjalankan pekerjaannya dapat diketahui. Sedangkan pada ayat 2 disebutkan bahwa "Peralatan pemantau dosis perorangan sebagaimana dimaksud dalam ayat (1) harus diolah dan dibaca oleh instansi atau badan yang telah terakreditasi dan ditunjuk oleh Badan Pengawas" [7].

Penetapan Nilai Batas Dosis (NBD) menurut Peraturan Badan Pengawas Tenaga Nuklir (BAPETEN) Nomor 01 Tahun 1999 bahwa Keselamatan radiasi dimaksudkan sebagai usaha untuk melindungi seseorang, keturunannya, dan juga anggota masyarakat secara keseluruhan terhadap kemungkinan terjadinya akibat biologi yang merugikan dari radiasi. Proteksi radiasi yang dilakukan untuk mengurangi pengaruh radiasi yang merusak akibat paparan radiasi, menjadi suatu keharusan untuk mewujudkan keselamatan radiasi [3]. Nilai Batas Dosis (NBD) untuk pekerja radiasi yang memperoleh penyinaran seluruh tubuh ditetapkan $20 \mathrm{mSv}$ per tahun, sedangkan NBD untuk anggota masyarakat dalam hal penyinaran seluruh tubuh, NBD untuk anggota masyarakat umum adalah $1 \mathrm{mSv}$ dalam setahun [4]. Sedangkan NBD untuk para magang dan siswa yang berumur serendah rendahnya 18 tahun, yang sedang melaksanakan latihan atau kerja praktek, atau yang karena keperluan pendidikannya terpaksa menggunakan sumber radiasi pengion, sama dengan NBD yang berlaku untuk pekerja radiasi [3].

Laboratorium Jurusan DIII Radiologi Universitas Baiturrahmah merupakan Laboratorium yang memiliki satu unit pesawat sinar-X konvensional dengan merk Acoma Tipe FCT 10 Nomor Seri 1K0071 yang dimanfaatkan oleh mahasiswa Jurusan DIII Radiologi untuk melakukan praktikum. Selama menyelesaikan perkuliahan mahasiswa wajib melaksanakan tiga mata kuliah praktikum yaitu praktikum Teknik radiografi 1, Teknik radiografi 2 dan Praktikum jaminan dan Kendali Mutu. Mahasiswa praktikum dibagi menjadi kelompok kecil yang terdiri dari 5-6 orang dan setiap kelompok mandapatkan 14 kali pertemuan. Dalam setiap pertemuan praktikum rata-rata alokasi waktu yang terpakai adalah 2 jam di dalam ruangan laboratorium. Sehingga mahasiswa akan menerima dosis radiasi eksternal selama melaksanakan kegitan praktikum tersebut.

\section{Efek Radiasi Terhadap Manusia}

Radiasi memiliki dua sifat yang khas, yaitu tidak dapat dirasakan secara langsung oleh panca indra manusia dan beberapa jenis radiasi dapat menembus berbagai jenis bahan. Pada saat melewati suatu bahan, radiasi pengion dapat mengalami proses ionisasi dan/atau proses eksitasi yang dapat menimbulkan efek foto listrik, hamburan Compton, juga efek produksi pasangan [8]. Radiasi yang mengenai tubuh manusia dapat menimbulkan kerugian. Efek radiasi dapat terjadi karena paparan akut yaitu paparan yang terjadi karena dosis paparan berlebih tunggal yang besar dan paparan kronis yaitu paparan yang dapat terjadi karena dosis kecil yang terus menerus dikenakan secara menahun [9]. Berdasarkan jenis sel yang terkena paparan radiasi efek radiasi dapat dibedakan atas efek genetik yaitu efek radiasi yang dirasakan oleh keturunan dari individu terpapar radiasi danefek somatik yaitu efek radiasi yang dirasakan oleh individu terpapar radiasi itu sendiri. Waktu yang dibutuhkan sampai terlihatnya gejala efek somatik ini sangat bervariasi sehingga dikenal efek segera yang secara klinik sudah dapat teramati dalam hitungan hari/minggu dan efek tertunda yang baru timbul setelah waktu tunda yang lama setelah terpapar radiasi [10].

Ditinjau dari dosis radiasi (untuk kepentingan proteksi radiasi), efek radiasi dibedakan atas efek stokastik yaitu efek radiasi yang munculnya tidak memerlukan 
Dela Nelvo Dasril: Pengukuran Dosis Eksternal Yang Diterima Oleh Mahasiswa Praktikum Teknik Radiografi di Laboratorium Radiologi Universitas Baiturrahmah Padang)

dosis ambang yang artinya dosis radiasi serendah apapun mempunyai kemungkinan untuk menimbulkan perubahan pada sistem biologi danefek deterministik yaitu efek radiasi yang timbul bila dosis yang diterima melebihi dosis ambang (threshold dose) dengan kualitas keparahannya bervariasi menurut dosis yang diterima dan hanya timbul bila dosis ambang dilampaui [8]. Efek radiasi terhadap tubuh manusia dapat terjadi karena paparan akut maupun paparan menahun (kronis) atau terusmenerus. Paparan akut berpengaruh kepada seluruh organ dan sistem tubuh karena dosis paparan berlebih tunggal yang besar sedangkan paparan terus menerut dapat terjadi karena dosis yang dikenakan secara menahun yang kecil. Efek dari paparan yang terus menerus adalah efek tertunda (late effect) seperti kanker, kanker tulang, kanker paru, leukemia dan lainnya [9].

Proteksi radiasi diperlukan untuk mencegah terjadinya efek deterministic dan mengurangi terjadinya efek stokastik serendah mungkin. Faktor utama untuk melindungi seseorang dari paparan radiasi adalah dengan sesingkat mungkin dan sejauh mungkin berada di sekitar sumber radiasi, serta memakai penahan radiasi, dengan pinsip proteksi radiasi yaitu justifikasi, optimasi dan limitasi. Penerimaan dosis radiasi pekerja radiasi dikendalikan dengan azaz limitasi dengan batasan Nilai Dosis yang ditetapkan $20 \mathrm{mSv} / \mathrm{tahun} \mathrm{[11].}$ Pengawasan NBD dilakukan dengan:

1. Pemantauan dosis perorangan

Pemantauan dosis perorangan dilakukan secara eksternal dan internal. Pemantauan eksternal dilakukan dengan menggunakan dosimeter perorangan dan pemantauan internal dilakukan secara invivo dan/atau in-vitro.

2. Pemantauan paparan radiasi daerah

Kerja Pemantauan paparan radiasi daerah kerja dilakukan untuk mencegah terlampauinya NBD, maka dilakukan pemantauan paparan radiasi daerah kerja, pengaturan waktu (lama) kerja dan pengaturan pekerja radiasi.

3. Pembatas dosis (dose constraint)

Pembatas dosis untuk penerapan optimasi proteksi radiasi dan keselamatan radiasi, agar besar dosis yang diterima pekerja radiasi serendah mungkin sesuai dengan prinsip ALARA (As Low As Reasonable Achievable) [12].

\section{Besaran dan Dosis Radiasi}

Besaran dan satuan dasar yang dipakai dalam pengukuran dosis radiasi telah didefinisikan oleh The International Commission of Radiation Units and Measurements (ICRU). Berikut ini adalah besaran dan satuan dasar dalam dosimetri:

\section{Dosis serap}

Besaran dosis serap digunakan untuk mengetahui jumlah energi dari radiasi pengion yang diserap oleh medium. Dosis serap ditunjukkan oleh Persamaan 1.

$$
D=d E / d m
$$

$D$ adalah dosis serap, $d E$ adalah energi yang diserap oleh medium bermassa $\mathrm{dm}$ dan $\mathrm{dm}$ adalah massa medium.

2. Dosis ekuivalen

Dosis ekuivalen merupakan besaran dosimetri yang berhubungan langsung dengan efek biologi, yang didapatkan dari perkalian dosis serap dengan faktor bobotnya. Dosis ekuivalen ditunjukkan oleh Persamaan 2.

$$
H_{T, R}=W_{R} D_{T, R}
$$

$H_{T, R}$ adalah dosis ekuivalen organ atau jaringan $\mathrm{T}$ dari radiasi $\mathrm{R}, W_{R}$ adalah faktor bobot dari radiasi $\mathrm{R}$ dan $D_{T, R}$ adalah dosis serap organ atau jaringan $\mathrm{T}$ dari radiasi $\mathrm{R}$. 
3. Dosis efektif

Dosis efektif diperlukan untuk menunjukkan keefektifan radiasi dalam menimbulkan efek tertentu pada suatu organ. Dosis efektif ditunjukkan oleh Persamaan 3.

$$
H_{E}=W_{T} H_{T}
$$

$H_{E}$ adalah dosis efektif, $W_{T}$ adalah faktor bobot organ atau jaringan $\mathrm{T}$, dan $H_{T}$ adalah dosis ekuivalen organ atau jaringan $\mathrm{T}$ [13].

\section{METODE PENELITIAN}

Penelitian ini menggunakan metode kuantitatif dengan pengambilan data secara langsung terhadap objek dengan menggunakan Thremoluminisensi Detector (TLD) badge yang dipasangkan pada saku baju bagian dada mahasiswa praktikum.

Populasi pada penelitain ini adalah seluruh mahasiswa angkatan 2018 yang melaksanakan praktikum di laboratorium Radiologi Universitas Baiturahmah yang berjumlah 50 mahasiswa. Seluruh mahasiswa tersebut dibagi menjadi 10 kelompok yang terdiri dari 5 mahasiswa dalam satu kelompok praktikum.

Sampel pada penelitian ini adalah menggunakan jenis purposive sampling yaitu pengambilan sampel yang berdasarkan atas suatu pertimbangan tertentu seperti sifat-sifat populasi ataupun ciri-ciri yang sudah diketahui sebelumnya [14]. Pengambilan sampel dilakukan hanya atas dasar pertimbangan penelitinya saja yang menganggap unsur-unsur yang dikehendaki telah ada dalam anggota sampel yang diambil [15]. Sehingga peneliti menentukan besar sampel yaitu $20 \%$ dari populasi dan didapatkan sampel 10 mahasiswa praktikum atau 2 kelompok praktikum.

Alat dan Bahan yang diguakan dalam penelitian ini adalah:

1. Pesawat Sinar-X konvensional merk Acoma Tipe FCT 10 nomor seri
$1 \mathrm{~K} 0071$.

2. TLD Badge 10 unit.

Penelitian ini dilaksanakan pada Juni Agustus 2019 di Laboratorium Jurusan DIII Radiologi Universitas Baiturrahmah Padang. Langkah-langkah penelitian adalah sebagai berikut:

1. Menyiapkan TLD badge sebanyak 10 unit yang telah dikalibrasi dan siap untuk digunakan.

2. Memasangkan TLD badge tersebut pada saku baju bagian dada mahasiswa selama 2 jam sebanyak 14 kali pertemuan praktikum.

3. Setelah praktikum selesai dalam tiap pertemuan maka TLD badge tidak digunakan lagi melainkan disimpan ditempat yang aman dari radiasi.

4. TLD badge dipasangkan kembali saat mahasiswa akan melaksanakan praktikum kembali.

Apabila praktikum selesai maka TLD Badge akan dikumpulkan dan dilakukan pembacaan nilai dosis dengan menggunakan TLD Reader pada PTKMR BATAN Jakarta. Teknik pengumpulan data pada penelitian ini adalah dengan mendapatkan nilai dosis yang terbaca pada TLD Badge yaitu dalam nilai dosis serap dan melakukan perhitungan untuk mendapatkan dosis ekivalen yang diterima oleh seluruh anggota tubuh tiap mahasiswa.

Analisa data dalam penelitian ini adalah membandingkan nilai dosis ekivalen yang diterima oleh seluruh tubuh dan membandingkan dengan NBD pekerja radiasi yang telah ditetapkan oleh peraturan Kepala Bapeten yaitu dosis ekivalen untuk seluruh tubuh adalah sebesar $20 \mathrm{mSv} /$ tahun.

\section{HASIL DAN PEMBAHASAN}

Penelitian tentang perhitungan dosis radiasi yang diterima oleh mahasiswa praktikum teknik radiografi di Labortorium 
Dela Nelvo Dasril: Pengukuran Dosis Eksternal Yang Diterima Oleh Mahasiswa Praktikum Teknik Radiografi di Laboratorium Radiologi Universitas Baiturrahmah Padang)

Radiologi universitas Baiturrahmah telah dilakukan. Pengukuran dosis dilakukan dengan mengunakan alat ukur dosis radiasi bagi pekerja radiasi yaitu TLD badge buatan Bhaba Atomic Research Centre (BARC) India. Dari bahan fosfor CaSO4:Dy untuk layanan pemantauan dosis eksternal perorangan yang mampu mendeteksi radiasi foton dan beta. Selan jutnyauntuk mendapatkan hasil bacaan dari TLD badge tersebut digunakan TLD Reader model 1010 buatan Nucleonix Systems (P) Ltd. - India.

Sebelum TLD Badge digunakan ada proses pengujian terhadap peralatan keselamatan pekerja radiasi yang terdiri atas 2 tahap yaitu: Kalibrasi filmbadge dan Pengujian/evaluasi dosimeter film.

Pada penelitian ini, Jenis TLD badge yang digunakan memiliki kriteria seperti yang ditunjukkan pada Tabel 1. Setelah dilakukan pembacaan TLD badge yang sudah digunakan, maka disadapatkan hasil pembacaan TLD dalam satuan $m S v$ yang ditunjukkan pada Tabel 2.

Berdasarkan penelitian yang telah dilakukan terhadap pengukuran dosis radiasi eksternal yang diterima oleh mahasiswa

Tabel 1. Kriteria TLD Badge yang digunakan

\begin{tabular}{|c|c|c|}
\hline Kriteria TLD & & Keterangan \\
\hline $\begin{array}{l}\text { Dimensi kartu } \\
\text { TLD }\end{array}$ & & $\begin{array}{l}52,5 \mathrm{~mm} \times 30 \mathrm{~mm} \times \\
1,0 \mathrm{~mm}\end{array}$ \\
\hline $\begin{array}{l}\text { Dimensi disk } \\
\text { TLD }\end{array}$ & & $13,3 \mathrm{~mm}$ diameter \\
\hline Open window & & $\mathrm{r}-14,5 \mathrm{~mm}$ \\
\hline Filter $\mathrm{Cu}$ & & $\begin{array}{l}30 \mathrm{~mm} \times 16 \mathrm{~mm} \times 1 \\
\mathrm{~mm}\end{array}$ \\
\hline Filter Al & & $\begin{array}{l}\text { Diameter } 15,6 \mathrm{~mm} \text {, } \\
\text { ketebalan } 1,0 \mathrm{~mm}\end{array}$ \\
\hline Filter plastik & & $\begin{array}{l}30,5 \mathrm{~mm} \times 21 \mathrm{~mm} \times \\
1,6 \mathrm{~mm}\end{array}$ \\
\hline $\begin{array}{l}\text { Puncak utama } \\
\text { (glowcurve) }\end{array}$ & & \\
\hline $\begin{array}{l}\text { Tanggapan } \\
\text { dosis linier }\end{array}$ & & $\begin{array}{lr}50 & \mu \mathrm{Sv} \\
(\text { gamma) } & -5 \mathrm{~Sv}\end{array}$ \\
\hline Tanggapan & & $100 \mu \mathrm{Sv}-5 \mathrm{~Sv}$ (beta) \\
\hline & & di bawah $5 \%$ \\
\hline
\end{tabular}

Tabel 2. Hasil pengukuran dosis dari TLD

\begin{tabular}{|c|c|c|}
\hline Nama Subjek & $\begin{array}{c}\text { Lama } \\
\text { pemakaian }\end{array}$ & $\begin{array}{c}\text { Dosis } \\
\text { eksternal }\end{array}$ \\
\hline Mahasiswa 1 & $\begin{array}{c}14 \text { kali } \\
\text { praktikum }\end{array}$ & 0 \\
\hline Mahasiswa 2 & $\begin{array}{l}14 \text { kali } \\
\text { praktikum }\end{array}$ & 0 \\
\hline Mahasiswa 3 & $\begin{array}{l}14 \text { kali } \\
\text { praktikum }\end{array}$ & 0 \\
\hline Mahasiswa 4 & $\begin{array}{c}14 \text { kali } \\
\text { praktikum }\end{array}$ & 0 \\
\hline Mahasiswa 5 & $\begin{array}{c}14 \text { kali } \\
\text { praktikum }\end{array}$ & 0 \\
\hline Mahasiswa 6 & $\begin{array}{l}14 \text { kali } \\
\text { praktikum }\end{array}$ & 0 \\
\hline Mahasiswa 7 & $\begin{array}{l}14 \text { kali } \\
\text { praktikum }\end{array}$ & 0 \\
\hline Mahasiswa 8 & $\begin{array}{c}14 \text { kali } \\
\text { praktikum }\end{array}$ & 0 \\
\hline Mahasiswa 9 & $\begin{array}{c}14 \text { kali } \\
\text { praktikum }\end{array}$ & 0 \\
\hline Mahasiswa 10 & $\begin{array}{c}14 \text { kali } \\
\text { praktikum }\end{array}$ & 0 \\
\hline
\end{tabular}

selama melaksanakan praktikum teknik radiografi dasar 1 selama 14 kali petemuan dengan menggunakan TLD badge yang dipasangkan pada bagian dada mahasiswa. Kegiatan penyinaran dilakukan oleh mahasiswa sebagai operator dan melaksanakan setiap kegiatan pemeriksaan yang ditentukan pada materi tersebut.

Berdasarkan Tabel 2. Bahwa nilai dosis eksternal yang diterima oleh mahasiswa pada saat melaksanakan praktikum teknik radiografi dasar di laboratorium radiologi Universitas Baiturrahmah selama 3 bulan pemakaian TLD dengan 14 kali pertemuan, dimana setiap pertemuan terdiri dari enam sampai dengan delapan kali ekspose dalam satu materi. Pada saat mahasiswa menjadi operator mereka berada pada pembatas dinding kontrol panel yang sudah dilapisi dengan timbal $(\mathrm{Pb})$ yang dapat menahan radiasi hambur. Dengan demikian mahasiswa berada pada daerah yang aman dari radiasi yaitu dengan jarak lebih dari 3 meter dari sumber radiasi. Pada saat melakukan ekspose mahasiswa tidak mengunakan Apron atau pelindung diri lainnya. 
Dari hasil nilai dosis eksternal yang didapatkan bahawa terlihat nilai tersebut masih sangat aman dan tidak terdapat nilai yang signifikan dengan menggunakan TLD badge tersebut. Karena hasil pembacaa TLD badge terbatas pada hasil miliSievert. Kemungkinan nilai yang ada pada radiasi alam lebih kecil dari pada miliSievert. Sehingga kemungkinan jika ada radiasi yang mengenai tubuh petugas atau mahasiswa tersebut kemungkinannya sangat kecil dalam rentang nilai mikroSievert.

\section{KESIMPULAN}

Berdasarkan nilai yang didapatkan dari penelitian ini dapat disimpulkan bahawa tidak terdapat radiasi hambur yang bernilai besar (dalam milliSievert) pada operator atau mahasiswa yang melakukan ekspose selama praktikum tersebut. Posisi mahasiswa pada saat menjadi operator sudah benar yaitu berada pada posisi bagian balakang dinding kontrol panel yang sudah dilapisi dengan timbal $(\mathrm{Pb})$ dengan jarak lebih dari 3 meter dari sumber radiasi.

\section{UCAPAN TERIMAKASIH}

Penulis mengucapkan terimakasih kepada Tim Laboratorium Radiologi, Program Studi DIII Radiologi, Fakultas Vokasi, Universitas Baiturahmah.

\section{DAFTAR PUSTAKA}

[1] D. R. Martem, D. Milvita, H. Yuliati, and D. D. Kusumawati, "Pengukuran Dosis Radiasi Ruangan Radiologi Ii Rumah Sakit Gigi dan Mulut (Rsgm) Baiturrahmah Padang Menggunakan Surveymeter Unfors-Xi," J. Fis. Unand, vol. 4, no. 4, pp. 414-418, 2015.

[2] D. Widyaningsih and S. Heri,
"Penentuan Dosis Radiasi Eksternal Pada Pekerja Radiasi Di Ruang Penyinaran Unit Radioterapi Rumah Sakit Dr.Kariadi Semarang," Berk. Fis., vol. 16, no. 2, pp. 57-62, 2013.

[3] Bapeten RI Badan Pengawas Tenaga Nuklir RI, "Keputusan Kepala Badan Pengawas Tenaga Nuklir Nomor 01/Ka-Bapeten/V-99 Tentang Ketentuan Keselamatan Kerja Terhadap Radiasi," Jakarta, 1999.

[4] Bapeten RI Badan Pengawas Tenaga Nuklir RI, "Peraturan Kepala BAPETEN Tentang Keselamatan Radiasi dalam Penggunaan Pesawat Sinar-X Radiologi Diagnostik dan Intervensional," Perka Bapeten No.8 /2011, 2011.

[5] T. Dianasari and H. Koesyanto, "Penerapan Manajemen Keselamatan Radiasi di Instalasi Radiologi Rumah Sakit," Unnes J. Public Heal., vol. 6, no. 3, p. 174, 2017.

[6] T. O. T. O. T. Rikasjono, E. L. S. Upriyatni, and H. E. B. Udiyono, "Radiasi Di Kawasan Batan Yogyakarta," SDM Teknol. Nukl., pp. 25-26, 2008.

[7] Presiden Republik Indonesia, "Peraturan Pemerintah Republik Indonesia Nomor 63 Tahun 2000 Tentang Keselamatan Dan Kesehatan Terhadap Pemanfaatan Radiasi Pengion," Jakarta, 2000.

[8] Zubaeda, "Efek Radiasi Pada Sistem Biologi," Asian Nucl. Saf. Network, Pendidik. dan Pelatih. BAPETENBATAN, 2006.

[9] E. Hiswara and D. Kartikasari, "Dosis Pasien Pada Pemeriksaan Rutin Sinar-X Radiologi Diagnostik," $J$. Sains dan Teknol. Nukl. Indones., vol. 16, no. 2, p. 71, 2015.

[10] W. S, Mengenal Azas Proteksi Radiasile. Bandung: FMIPA Institut Teknologi Bandung, 1995.

[11] R. D. Rps, A. I. Nugroho, and B. B. P, "Kajian aspek keselamatan dalam 
Dela Nelvo Dasril: Pengukuran Dosis Eksternal Yang Diterima Oleh Mahasiswa Praktikum Teknik Radiografi di Laboratorium Radiologi Universitas Baiturrahmah Padang)

penanganan penerimaan dosis radiasi eksterna berlebih di prr," 2012.

[12] BATAN, "Pedoman Keselamatan dan Proteksi Radiasi Kawasan Nuklir Serpong," 2011.

[13] M. Akadi, Dasar-Dasar Proteksi Radiasi. Jakarta: Pt. Rineka Cipta, 2000.

[14] S. Notoatmodjo, Metodologi
Penelitian Kesehatan. Jakarta: PT. Rineka Cipta, 2012.

[15] R. Nasution, "Teknik Sampling," Fakultas Kesehatan Masyarakat, Universitas Sumatera Utara, 2003. [Online]. Available: www.library.usu.ac.id. [Accessed: 10-Dec-2018]. 